\title{
Comunicação da morte: modos de pensar e agir de médicos em um hospital de emergência
}

I ${ }^{1}$ Gislaine Alves Souza, ${ }^{2}$ Karla Giacomin, ${ }^{3}$ Janaína Souza Aredes, ${ }^{4}$ Josélia Oliveira Araújo Firmo I

Resumo: Este estudo objetivou compreender como os médicos lidam com o processo de comunicar a morte aos familiares em um hospital de emergência. Trata-se de uma pesquisa qualitativa, embasada na antropologia interpretativa e médica. A coleta dos dados deu-se em um dos maiores hospitais públicos de emergência da América Latina, ao longo de nove meses de observação participante. Foram entrevistados 43 médicos. A análise foi êmica e guiada pelo modelo dos signos, significados e açóes. Embora a morte seja um evento frequente pela gravidade dos casos atendidos, os médicos percebem as vivências da comunicação do óbito como uma das tarefas mais árduas do seu fazer profissional. Fazem uso de roteiros, eufemismos, mecanismos defensivos, enfatizam a gravidade clínica e informam progressivamente sobre o agravamento do quadro, para que a morte seja aguardada pela família e encaixada na rotina da emergência. Os signos e significados estão especialmente correlacionados ao paradigma biomédico, veem o fato como tabu e fracasso, enquanto as açóes evidenciam a morte e a interação intersubjetiva como terreno obrigatório de emoçôes, que ocorrem escondidas pelo profissional. Os elementos apontados podem subsidiar intervençôes, planejamento e gestão na atenção à saúde, no âmbito da educação, saúde do trabalhador e organização institucional.

> Palavras-chave: morte; comunicação; antropologia médica; serviço hospitalar de emergência; médicos.
${ }^{1}$ Instituto René Rachou, Fundação Oswaldo Cruz. Belo HorizonteMG, Brasil (gislaine.as@gmail.com). ORCID: 0000-0002-4556-2416

${ }^{2}$ Instituto René Rachou, Fundação Oswaldo Cruz. Belo Horizonte-MG, Brasil (kcgiacomin@hotmail.com). ORCID: 0000-0002-9510-6953

${ }^{3}$ Instituto René Rachou, Fundação Oswaldo Cruz. Belo Horizonte-MG, Brasil (janainaaredes@gmail.com). ORCID:0000-0002-4147-2405

${ }^{4}$ Instituto René Rachou, Fundação Oswaldo Cruz. Belo Horizonte-MG, Brasil (firmoj@minas.fiocruz.br). ORCID: 0000-0001-5330-476X

Recebido em: 04/01/2018 Revisado em: 13/06/2018 Aprovado em: 22/09/2018 


\section{Introdução}

A consciência, a atitude e a emoção frente a morte são fenômenos determinados social e historicamente e influenciados pela cultura (ARIÈS, 2014; TIMMERMANS, 2005). Na sociedade Ocidental, a partir da Revolução Industrial, a morte foi inserida na lógica de produção, institucionalizada em asilos e hospitais, silenciada e banida da comunidade. Após a Segunda Guerra, ela é vista como uma adversidade sendo rechaçada do cotidiano social: o processo de morrer vivenciado pelo doente sai do âmbito familiar e migra para os cuidados médicos. A morte se "profissionaliza": compartimentalizada pelo médico, medida por aparelhos, institucionalizada em hospitais e quase reduzida a uma mera notícia (PITTA, 2016; ARIÈS, 2014; TIMMERMANS, 2005; ILLICH, 2003). Quando ocorre é demarcado como papel do médico comunicar o fato à família (SILVA; RAMOS, 2014; SHOENBERGER et al., 2013). Contudo, mesmo em ambientes hospitalares e entre profissionais médicos, a comunicação da morte ainda é acompanhada por inú meras dificuldades (LAMBA et al., 2015; SILVA; RAMOS, 2014; REYNIERS et al., 2014; SHOENBERGER et al., 2013; TAPAJÓS, 2007).

No campo da saúde, comunicar não é apenas transmitir informação técnica e unidirecional; trata-se de uma maneira de interagir que depende do contexto e se mostra indissociável das vivências, dos significados e da produção de sentidos (STELET; CASTIEL; MORAES, 2017; ARAÚJO; CARDOSO, 2007). É no universo sociocultural que se enraízam os modos de pensar e agir, sendo fundamental compreendê-lo para uma maior efetividade das intervençóes de saúde (UCHÔA; VIDAL, 1994). De modo similar, a comunicação em saúde é uma construção e uma prática social, complexa, multipolar e multidimensional, que envolve aspectos psicossociais, afetivos, cognitivos, culturais, contextuais, bioéticos, religiosos, espirituais, econômicos, políticos e legais (AFONSO; MINAYO, 2013; SANTOS; MORAES; MASSAROLLO, 2012; ARAÚJO; CARDOSO, 2007).

Dada a escassez de estudos sobre a vivência da morte pelos médicos no ambiente hospitalar, emerge a necessidade de pesquisas que considerem a percepção desses profissionais quanto à comunicaçáo de notícias difíceis (AFONSO; MINAYO, 2013; DELL'ACQUA; TOME; POPIM, 2013).

No âmbito das urgências e emergências, comunicar a morte também configura uma tarefa árdua, estressante, dolorosa, ainda que essencial aos médicos que 
prestam pronto atendimento (LAMBA et al., 2015; ASCENCIO-ROMERO, 2015; SHOENBERGER et al., 2013). Porém, as publicaçôes concentram-se mais em modelos, protocolos e recomendaçôes técnicas para a comunicação (ASCENCIOROMERO et al., 2015; LAMBA et al., 2015; FALCONI-CHALCO, 2013; SHOENBERGER et al. 2013;) do que em tensôes éticas transversais à morte (SANTOS; MORAES; MASSAROLLO, 2012).

Assim, este estudo investiga a experiência de comunicação da morte por médicos, na condição de sujeitos culturais que atuam em um hospital metropolitano de emergência, com o objetivo de compreender como lidam com o processo.

\section{Procedimentos metodológicos}

Trata-se de uma pesquisa qualitativa (MINAYO, 2017) ancorada no referencial teórico-metodológico da Antropologia Interpretativa (GEERTZ, 1989) e Médica (UCHÔA; VIDAL, 1994). Nessas vertentes é por intermédio dos padrôes culturais que os eventos se tornam inteligíveis e os indivíduos de um grupo encontram sentido, interpretam e guiam suas açôes (GEERTZ, 1989; UCHÔA; VIDAL, 1994). A Antropologia Médica estuda os modos de agir e de pensar dos sujeitos relacionados à saúde, considerando-os experiências envoltas por significados conectados ao meio sociocultural (UCHÔA; VIDAL, 1994). Distingue dois aspectos indissociáveis no fenômeno saúde-doença: disease - processo biológico e de diagnóstico médico — e illness - experiência humana psicossocial da doença, construção cultural, seja individual ou coletiva, que conjuga normas, expectativas e valores que se expressam nos modos típicos de pensar e agir (UCHÔA; VIDAL, 1994).

O estudo foi realizado em um complexo de urgência e emergência do Sistema Único de Saúde localizado no hipercentro de uma metrópole brasileira e referência na América Latina. Para imersão no universo sociocultural dos médicos desta instituição, a coleta de dados foi realizada ao longo de nove meses de observação participante e entrevistas guiadas por roteiro semiestruturado. A população estudada foi composta por participantes voluntários, convidados em seu turno e local de trabalho, quais sejam: médicos da Porta de Entrada (setores: bloco cirúrgico e sala de recuperação, sala de politraumas, sala de emergências clínicas), das Unidades de Terapia Intensiva (para adultos, crianças e queimados graves) e da Unidade de Cuidados Progressivos (destinada aos pacientes com sequelas graves e definitivas). 
Na seleção, um entrevistado indicava outro, método denominado "bola de neve" (PATTON, 2002). O coordenador de cada setor foi o indivíduo-chave que facilitou o contato com os profissionais. Foram critérios de inclusão: atuar em setores específicos para pacientes graves com risco de morte e aceitar participar da pesquisa. Não houve nenhuma recusa à participação.

Foram entrevistados 43 médicos, sendo 25 homens e 18 mulheres, com idades entre 28 e 69 anos, especialistas em cirurgia (geral, trauma, neurocirurgia e cardiovascular); anestesia; clínica médica; terapia intensiva; pediatria; cardiologia; nefrologia; oncologia. Quanto ao tempo de graduação: 30\% dos entrevistados têm abaixo de nove anos de formados; $40 \%$, entre 10 e 29 anos; e 30\%, mais de 30 anos. Sobre o vínculo com o hospital, $77 \%$ são plantonistas e $23 \%$ estáo em função de coordenação.

A coleta de dados foi encerrada quando a qualidade, a quantidade e a intensidade do material permitiam evidenciar a complexidade e possibilitar a imersão no universo sociocultural (MINAYO, 2017). Ao longo da coleta houve o registro das observaçôes em um diário de campo. Essa ferramenta e todas as entrevistas, gravadas e transcritas, foram analisadas.

A análise dos dados foi fundamentada no modelo de "signos, significados e açôes". Nele, inverte-se a lógica usual: parte-se das açôes dos atores em seu ambiente, para aceder ao nível semântico desse sistema cultural. A grade de codificação comporta: a pragmática do discurso; o conteúdo de informaçôes predominante; os níveis de análise entre cada um dos signos, significados e ações; e a relação entre esses níveis, quais pontos nodais e de conexáo (CORIN et al., 1992). A análise, composta por 5 etapas, visou compreender a comunicação da morte, a partir da: leitura em profundidade das entrevistas e diários de campo; categorização dos dados em planilha do Excel; análise pelas autoras da compatibilidade da categorização; reunião para revisão da categorização dos dados; escrita dos resultados. Trabalhou-se com dois grandes temas "Comunicar a morte do paciente" e "O médico e a morte". As açôes, reaçóes e atitudes dos médicos foram o acesso privilegiado para a identificação dos signos, significados e interpretaçóes desses profissionais no processo de comunicar a morte, considerando o contexto cultural e o universo partilhado do hospital de emergência. Os interlocutores assinaram o termo de consentimento livre e esclarecido e assegurou-se o sigilo, sendo os entrevistados identificados pela letra "E" seguida de numeração, especialidade, sexo (F para feminino, M para masculino) e idade. 
Este artigo integra um estudo maior intitulado "Vidas em risco: uma abordagem antropológica sobre as representaçôes da morte entre médicos que trabalham em setores de urgência” e está em acordo com a Resolução no 466/2012 e no 510/2016 do Conselho Nacional de Saúde.

\section{Resultados e Discussão}

$\mathrm{Na}$ ação de comunicar o óbito de um paciente no hospital de emergência, os interlocutores discorrem sobre a relação que estabelecem com a família do morto, como neste excerto:

Isso [a relação com os familiares] é um ponto que aqui precisa melhorar, porque a relação com a família é muito institucional. Alguns [médicos] são mais acessíveis, outros se escondem dentro do gigantismo da instituição e nem acessam a família nem conversam, mas eu acho que isso deveria ser melhorado. (E1, Cirurgia Cardiovascular, M, 53 anos).

A maioria dos médicos é plantonista, narra ter pouco vínculo com o público atendido e envolvimento quase inexistente com o familiar. Em alguns momentos, a comunicação ocorre sem conversas prévias, sem saber quem é a pessoa da família e com poucas informaçôes sobre o falecido. Eles afirmam que a interação com o familiar se dá de modo rápido, superficial, impessoal, tenso e confuso, além de ser difícil conciliar a atenção à família com a dinâmica da emergência. O cuidado segmentado também concorre para uma comunicação deficitária, precária ou ruim (MONTEIRO et al., 2015; DESLANDES, 2002), pois muitos encontros se dão no automatismo da rotina do serviço (SILVA; RAMOS, 2014).

Embora à época da pesquisa houvesse uma sala de acolhimento específica para a notícia do óbito, que era utilizada por alguns profissionais, outros queixavamse da inexistência de lugar apropriado e de privacidade, e comunicavam-na nos corredores do hospital.

Sobre como comunicam a morte, descrevem que o médico responsável pelo acompanhamento do caso se dirige a um parente — ou acompanhante — do paciente e informa o óbito. Alguns profissionais utilizam estratégias que designam como "roteirinho", "tática", "rodeio danado", "ir matando devagarinho o paciente", em uma sequência: apresenta-se como médico; pergunta qual é o grau de parentesco da pessoa com o falecido; retoma como a pessoa chegou ao hospital; descreve os procedimentos técnicos realizados; narra a evolução clínica e as manifestaçôes biológicas finais do processo. Todavia, em substituição à palavra morte, utilizam 
outros termos, para finalmente comunicar como e por que o paciente morreu. Ao narrar experiências de comunicação, frequentemente utilizam o pronome pessoal na terceira pessoa do singular e o verbo no passado: "ele faleceu" ou "não resistiu", e os advérbios "não" e "infelizmente". Como exemplifica o excerto:

O seu parente sofreu um acidente, ele chegou num estado muito grave, em coma. Falo o que foi feito para evitar, falo que foi reanimado, que foram realizados todos os exames, explico o tipo de coágulo que deu, e falo que infelizmente não foi possível, de maneira que o corpo da pessoa não aguentou os traumas que recebeu. Geralmente eu falo: não resistiu. (E15, Neurocirurgia, M, 40 anos)

Muitas vezes, a comunicação ocorre priorizando o modelo informacional, unilateral, linear e o aspecto biológico. Tal padrão desconsidera a dinâmica da linguagem e dos significados dos códigos, a multiplicidade de vozes em cada enunciado, como também os aspectos afetivos, cognitivos, políticos, econômicos, a cultura, os grupos sociais e o seu contexto (ARAÚJO; CARDOSO, 2007).

De forma geral, no contexto investigado, os médicos, seguindo-se à notícia do óbito, encaminham diretamente o familiar ao setor do serviço social e de psicologia para o suporte necessário. Este médico esclarece:

Nunca é bom perder um paciente, então, por mais grave que o paciente apareça [...] mesmo estando isso na minha rotina, é desagradável lidar com essas situações [...] talvez pelo fato que seja ruim lidar com essa questáo da morte, nenhum médico quer perder o seu paciente [...] A imensa maioria dos plantonistas da urgência do hospital, ele não tem nem tempo de se envolver com o paciente. De qualquer forma, existem algumas situaçóes que nos chocam [...] é claro que há situaçóes que mexem com os nossos sentimentos, e tenho certeza que isso acontece com todo mundo mesmo que ele não demonstre isso, porque o perfil do cirurgião é de um cara durão. (E11, Cirurgia Geral, M, 39 anos).

Essa dificuldade na comunicação do óbito está de acordo com outros estudos (PEREIRA et al., 2017; FALCONI-CHALCO, 2013; SANTOS; MORAES; MASSAROLLO, 2012). Alguns discutem que os profissionais de saúde experientes se sentiriam mais preparados para lidar com a morte (SHOENBERGER et al., 2013); outros afirmam que mesmo aqueles que automatizam a rotina com a morte vivenciam conflitos, dado o inevitável envolvimento subjetivo (DELLACQUA; TOME; POPIM, 2013).

No universo pesquisado, mesmo para profissionais muito experientes, a ação de comunicar a morte é árdua, como explica este médico:

Eu trabalho no CTI daqui há 37 anos [...] eu tenho muita dificuldade é para dar notícia de morte. Não (me) acostumo mesmo, toda vez que no nosso serviço falece algum pa- 
ciente, eu fico angustiado por ter que dar a notícia [...]. Essa parte é a mais triste, é a pior hora do plantão médico, da atuaçáo médica, da nossa profissão. Dar essa notícia me deixa sempre muito chateado. (E35, Clínica Médica, M, 69 anos)

Portanto, ainda que a experiência profissional no decorrer dos anos melhore a habilidade de comunicação, parte dos profissionais experientes também se sente despreparada (ALELWANI; AHMED, 2014). O detalhamento das especificidades para compreensão desse processo será abordado nas categorias analíticas: "a emergência como contexto em que a comunicação de morte ocorre"; "os signos e os significados atribuídos à comunicação da morte: o paradigma biomédico e seus paradoxos"; "as reaçôes e emoçôes ao comunicar a morte ao familiar".

\section{A emergência como contexto em que a comunicaçáo de morte ocorre}

Pano de fundo que interage e articula com as demais categorias é o contexto institucional em que ocorre a comunicação do óbito. No cenário estudado, encontram-se de graves politraumas, queimaduras, intoxicação a situações cirúrgicas ou clínicas, incluindo pessoas na chamada situação in extremis - com risco iminente de morte. Diferentes aspectos desse contexto interferem em como os médicos lidam com a comunicação da morte. Destacam-se:

- Defasagem na formação biomédica no que se refere a: habilidades interpessoais e comunicativas para lidar com choros, súplicas, desespero, negação dos diferentes atores; incipiência de concepçôes de morte como parte integrante da vida e abordagens de dignidade na morte; estranhamento em sustentar medidas náo invasivas ou aceitar que um paciente está fora de possibilidades curativas;

- Atuação predominantemente técnica, segmentada e ancorada na cultura intervencionista irrefletida na emergência: tempo, atenção e ambiente dedicados à medicina curativa e à emergência, utilizados como justificativa e "escudo" para não interagir; inexistência de construção de relacionamento e vínculo prévio com o paciente e a família/responsável desconhecendo valores e informaçôes individuais;

- Cultura institucional: cobranças e pressóes de outros colegas, da instituição, do sistema de saúde e de familiares que tendem a lutar contra a morte e exigem do profissional que silencie suas emoçôes;

- Condiçốes de trabalho: grande demanda de assistência médica devido à quantidade e à gravidade dos quadros traumáticos e clínicos; após noticiar uma morte, o plantão prossegue; ânimos exaltados de familiares e dos profissionais; 
- Circunstâncias da morte: em sua maioria abruptas, de pacientes jovens e previamente hígidos; situaçóes pessoais e sociais que tornam a comunicação mais difícil, como a identificação do profissional quando morre uma criança ou um trabalhador.

Em outras pesquisas, o contexto da emergência também é reconhecido pela grande demanda de atendimento em volume e diversidade; profissionais sobrecarregados; população exigente; insuficiência de espaço físico; ausência de privacidade; restrição de tempo; cuidado fragmentado; qualidade da assistência diminuída; falta de conhecimento sobre o paciente, a família e suas necessidades; falta de recursos materiais, humanos, psíquicos e de rede para contrarreferência (SILVA; RAMOS, 2014; DELL'ACQUA; TOME; POPIM, 2013).

A abordagem nos corredores, competindo com as ações em tempo real (LIMEHOUSE et al., 2012) ou com a morte que acontece em situação de dor severa, choque, ansiedade e desespero (NORDBY; NOHR, 2008) ou inesperada e mais difícil para os sobreviventes (SHOENBERGER et al., 2013) — interfere na qualidade da comunicação do óbito no pronto atendimento.

Além disso, nesse contexto, outros fatores - culturais, falta de relacionamento prévio, limitação do ambiente e tempo, de privacidade e conforto aos familiares (LAMBA et al., 2015; SHOENBERGER et al., 2013; FORERO et al., 2012) tornam a comunicação rasa, contraditória, imprecisa e onerosa para o paciente no fim de vida e sua família (REYNIERS et al., 2014; LIMEHOUSE et al., 2012).

Na emergência, observa-se uma confiança excessiva na biotecnologia e a negação da morte (ARIĖS, 2014; DELL'ACQUA; TOME; POPIM, 2013; AFONSO; MINAYO, 2013) de acordo com o estabelecido no paradigma biomédico (CAMARGO JR, 2013; FORERO et al., 2012), como será apresentado na próxima categoria.

\section{Os signos e os significados atribuídos à comunicação da morte: o paradigma biomédico e seus paradoxos}

No contexto pesquisado, ao ter de comunicar uma morte, os médicos evitam nomeá-la de modo explícito. Lançam mão de outros signos, conforme detalhado no quadro 1. 
Quadro 1. Signos utilizados em substituição a palavra "morte"

\begin{tabular}{|c|c|}
\hline Signos & Fragmentos das entrevistas \\
\hline $\begin{array}{l}\text { Perdemos; não foi } \\
\text { possível; não tive êxito; } \\
\text { não consegui; não } \\
\text { conseguimos. }\end{array}$ & $\begin{array}{l}\text { [...] "digo que infelizmente eu não tive êxito e o paciente veio a óbito" } \\
\text { (E22, Clínica Médica, M, } 33 \text { anos). } \\
\text { "Aí eu falo: olha, nós perdemos. Infelizmente nós estávamos numa } \\
\text { luta danada para mantê-lo vivo, mas nós não conseguimos" (E33, } \\
\text { Terapia Intensiva, F, } 34 \text { anos). }\end{array}$ \\
\hline $\begin{array}{l}\text { Partiu; incompatível } \\
\text { com a vida. }\end{array}$ & $\begin{array}{l}{[\ldots] \text { "infelizmente ele já partiu" (E41, Clínica Médica, M, } 38 \text { anos). }} \\
{[\ldots] \text { "digo que ele é incompatível com a vida" (E8, Cirurgia Geral, }} \\
\text { M, } 58 \text { anos). }\end{array}$ \\
\hline $\begin{array}{l}\text { Faleceu; não resistiu; } \\
\text { não aguentou; ele não } \\
\text { respondeu }\end{array}$ & $\begin{array}{l}\text { [...] "ele faleceu" (E4, Anestesiologia, F, } 33 \text { anos). } \\
\text { "Geralmente eu falo que 'infelizmente ele não resistiu e acabou } \\
\text { falecendo" (E11, Cirurgia Geral, M, } 39 \text { anos). }\end{array}$ \\
\hline $\begin{array}{l}\text { Tentamos de tudo; ele } \\
\text { lutou, nós lutamos; ele } \\
\text { complicou }\end{array}$ & $\begin{array}{l}{[\ldots] \text { "nós fizemos todas as tentativas possíveis para reverter as lesóes e }} \\
\text { as complicaçóes, mas infelizmente ele não respondeu a nenhuma das } \\
\text { nossas tentativas e foi a óbito" (E37, Pediatria, F, } 58 \text { anos). } \\
{[\ldots . .] \text { "a lesão foi muito mais forte que o doente, ele lutou, lutou, nós }} \\
\text { lutamos, mas a doença foi muito mais forte do que ele" (E41, Clínica } \\
\text { Médica, M, } 38 \text { anos). }\end{array}$ \\
\hline $\begin{array}{l}\text { Aconteceu o pior; a } \\
\text { notícia não é boa }\end{array}$ & $\begin{array}{l}\text { [...] "infelizmente aconteceu o pior e o paciente faleceu" (E31, Clínica } \\
\text { Médica, M, } 58 \text { anos). } \\
\text { [...] "digo que infelizmente as notícias não são boas, depois explico } \\
\text { tecnicamente o que aconteceu, volto na evolução do paciente. Eu falo } \\
\text { que a notícia não é boa e tudo" (E20, Clínica Médica, F, } 47 \text { anos). }\end{array}$ \\
\hline $\begin{array}{l}\text { Sobreviveria } \\
\text { vegetando; ele estava } \\
\text { sofrendo }\end{array}$ & $\begin{array}{l}{[\ldots . .] \text { "se ele tivesse sobrevivido, ele iria sobreviver vegetando [...] Para }} \\
\text { ele, é melhor ir do que vegetar [...] se ele sobrevivesse ele iria sobreviver } \\
\text { às custas de sequelas irreversíveis." (E19, Neurocirurgia, M, } 32 \text { anos) } \\
\text { "Eu costumo mostrar o outro lado, dizer que o paciente estava } \\
\text { sofrendo muito" (E32, Clínica Médica, F, } 56 \text { anos). }\end{array}$ \\
\hline
\end{tabular}

Fonte: Elaborado pelas autoras.

No hospital, nomear a morte é culturalmente embaraçoso e desconfortável (PITTA, 2016; ARIÈS, 2014). Observa-se que o universo dos signos relevantes para os interlocutores se apoia no corpo físico, no biológico. Predomina a necessidade de garantir que intervieram ao máximo para evitar o óbito, sendo este compreendido 
como uma adversidade, o pior desfecho, uma má notícia. Por outro lado, alguns profissionais, mais analíticos quanto ao processo vivenciado em sua prática, sinalizam que viver sofrendo por uma sequela crônica e grave poderia ser pior que a morte (AREDES; GIACOMIN; FIRMO, 2018), evidenciando os paradoxos do cotidiano na emergência.

O uso de eufemismos é recorrente, como explica esta entrevistada:

Eu sou muito clara, não uso muito a palavra morte, mas sim, não resistiu, faleceu (E30, Clínica Médica, F, 44 anos).

Tal uso visa amenizar o impacto da notícia, mas os aspectos semânticos continuam os mesmos, servindo mais ao profissional que ao receptor da mensagem (TAPAJÓS, 2007). No cenário pesquisado, os profissionais substituem a palavra morte, tabu inominável, que assusta, causa vergonha, sofrimento e é "estranho" ao médico (SILVA; MENEZES, 2015; REYNIERS et al., 2014). Trata-se de uma estratégia e reação emocional para afastar a angústia e amenizar a percepção de fracasso e impotência da medicina (SILVA; MENEZES, 2015; MONTEIRO et al., 2015; ARIĖS, 2014). Assim, apesar de determinações técnicas orientarem que a fala deva ser direta sobre a morte (PEREIRA et al., 2017; FALCONI-CHALCO, 2013; SHOENBERGER et al., 2013), nesta etnografia, o termo "morte" somente foi utilizado quando tentativas de explicação anteriores falharam.

Percebe-se também que o sentido da comunicação é construído no contexto e perpassa a fala progressiva sobre a gravidade do caso. $\mathrm{Na}$ mensagem, reflexo da formação biomédica, os profissionais apresentam a morte objetivada, fragmentada, e como o resultado do seu fracasso individual, como transparece na fala "lutei e perdi”. Embora os interlocutores assumam que comunicar a morte deveria ser uma tarefa conjunta dos profissionais envolvidos no cuidado ao paciente, decisóes compartilhadas pouco aparecem.

Ao responder o que é a morte e como lidam com esse fenômeno, médicos de diferentes gêneros, idades e especialidades esclarecem:

A morte é o fim, eu não consigo vislumbrar muito o que vem depois. E nós, médicos, brigamos muito para não ter óbito, até excedemos em investimento e não podemos deixar aquilo acontecer. É muito doído para o médico perder um paciente. [...] Até o paciente ir a óbito é uma luta, tanto uma luta para deixar o paciente vivo, como também uma luta interna "eu não posso deixar esse paciente morrer". A gente não consegue ter um desapego como deveria. Eu acho que isso é reforçado pela sociedade ocidental, onde as pessoas não aceitam a morte. (E3, Anestesiologia, F, 42 anos). 


\begin{abstract}
$\mathrm{Na}$ verdade, a crença de que existe uma outra vida e que existe uma continuidade é propagada em filmes, e dada nos veículos religiosos que destoa, eu acho, do comportamento das pessoas. Embora seja passada essa forma sutil e poetizada da morte, ela é ainda algo que amedronta, algo que não é fácil de lidar. (E6, Anestesiologia, M, 33 anos).

Claro que a gente tem dificuldades em lidar com limites, na medicina a gente às vezes passa do limite em muitos aspectos, muitos plantonistas têm essa coisa: ah, vou passar esse paciente para o próximo plantão, ele não vai morrer no meu plantão. [...] Passar o paciente por não querer que ele morra no seu plantáo, porque vão falar que eu sou um mau médico, daí eu tenho que dar a notícia para a família e eu não quero passar por isso. (E40, Clínica Médica, M, 29 anos).
\end{abstract}

Observa-se o sofrimento do profissional por ser o portador oficial da notícia da morte. Visualiza-se em campo que as múltiplas significaçōes pessoais, culturais, religiosas em torno da morte coexistem com a lógica biomédica, muitas vezes de modo ambivalente. Dentre as motivaçôes para as dificuldades dos médicos diante da morte encontram-se as expectativas do saber biomédico e da sociedade em salvar vidas, principalmente nos serviços de emergência. Não sabem como comunicar algo que não lhes foi apresentado como uma possibilidade do cuidado médico, em virtude da frágil discussão sobre a morte na formação médica. Sofrem com a perspectiva da mortalidade, da falibilidade e dos limites que cada óbito vivenciado na emergência lhes obriga a admitir e a comunicar. Relatam carregar "sacos de vida e mortes", "armários com suas mortes e histórias" (Diário de campo, 2013). Reveem as mortes dos pacientes assistidos, sentem-se angustiados e culpados porque na lógica biomédica algo deveria ter sido feito, ou ainda, frustrados quando se envolvem ou identificam com o momento de vida experimentado pelo paciente.

Para a emergência e o modelo biomédico hegemônico, a visão predominante é da morte como resultado de uma disfunção orgânica, a ser tratada e evitada com todos os recursos técnicos e humanos disponíveis (REYNIERS et al., 2014; DELL'ACQUA; TOME; POPIM, 2013; TIMMERMANS, 2005; ILLICH, 2003). Por isso, nota-se uma satisfação do profissional quando consegue a sobrevida e sentimentos de insucesso, fracasso e impotência quando a morte prevalece (AREDES; MODESTO, 2016; SILVA; MENEZES, 2015; ARIÈS, 2014). No contexto específico da emergência, cuja cultura organizacional é de agir rápido para salvar vidas (DESLANDES, 2002), o moribundo é visto como a prova da derrota da medicina na luta contra a morte (PITTA, 2016; MONTEIRO et al., 2015; ARIÈS, 2014; AFONSO; MINAYO, 2013; ILLICH, 2003). Em campo observa-se que a morte deixa o médico duplamente desconfortável, por ferir sua expectativa de ser 
capaz de garantir a sobrevivência do paciente e por gerar a demanda da comunicação do óbito à família (MONTEIRO et al., 2015).

Na lógica biomédica, limita-se a função dos médicos a domesticar a morte (PITTA, 2016; ARIÈS, 2014; DELL'ACQUA; TOME; POPIM, 2013; ILLICH, 2003), encaixála na rotina hospitalar e enquadrá-la-ao modo culturalmente aceito (TIMMERMANS, 2005). Justificam o procrastinar a morte para garantir à família ter utilizado todos os recursos disponíveis e possibilitar receber melhor e gradualmente a comunicação (FALCONI-CHALCO, 2013; LIMEHOUSE et al., 2012). Porém, nesse movimento, definem intervençôes técnicas, sem questionar sobre seu limite diante da morte, sobre a repercussão da sua obstinação junto aos familiares e à sociedade, bem como sobre o que é a vida não apenas no âmbito biológico, mas também as suas reaçôes no aspecto social e cultural, como será abordado na próxima categoria.

\section{As reaçóes e emoçóes ao comunicar a morte ao familiar}

Visualizam-se as reaçóes vivenciadas no processo de comunicação da morte por médicos que atuam na emergência, sintetizadas no quadro 2 .

Quadiro 2. Reaçóes relatadas ao comunicar a morte

\begin{tabular}{|c|l|}
\hline Reaçóes & \multicolumn{1}{c|}{ Fragmentos das entrevistas } \\
\hline \multirow{6}{*}{ Chorar } & $\begin{array}{l}\text { "Eu quase sempre me emociono, tem dia que eu consigo ser durona, tem dia } \\
\text { que não." (E5, Anestesiologia, F, 32 anos) "Muitas vezes a gente vai para o } \\
\text { banheiro, chora, e depois volta fazendo cara de paisagem.” (E7, Anestesiologia, } \\
\text { F, 35 anos) "Teve um menino de uns } 8 \text { anos, ele teve um traumatismo bobo, } \\
\text { ele caiu do cavalo, o cérebro dele inchou muito. Eu coloquei um monitor } \\
\text { de pressão intracraniana, depois ele começou a inchar muito e tivemos que } \\
\text { fazer uma cirurgia descompressiva e ele morreu um tempo depois. Ele teve } \\
\text { a princípio um inchaço cerebral, eu até falei para a família que ia dar tudo } \\
\text { certo, porque não era muito grave, mas deu tudo completamente errado, e a } \\
\text { família veio atrás de mim, veio agradecer, eu ficava me perguntando por que } \\
\text { eles estavam me agradecendo, porque eu tinha dito que ia dar tudo certo, } \\
\text { mas deu tudo errado e a família me deu alguns poemas que esse menino } \\
\text { fez e eu tenho isso guardado até hoje (se emociona). E isso é surpreendente } \\
\text { porque há estudos, pesquisas que revelam o que vai dar certo e o que vai } \\
\text { dar errado. Entáo, quando dá errado quando era para dar certo a gente fica } \\
\text { muito assustado." (E18, Neurocirurgia, M, 34 anos) "Muitas vezes eu encho } \\
\text { os olhos d'água, choro junto." (E28, Terapia Intensiva, F, 49 anos) }\end{array}$ \\
\hline
\end{tabular}

continua... 


\begin{tabular}{|c|c|}
\hline Angustiar-se & $\begin{array}{l}\text { "Não vou dizer que é fácil, porque toda vez que tenho que dar a notícia para } \\
\text { alguém me dá um aperto no peito." (E4, Anestesiologia, F, } 33 \text { anos) "Não } \\
\text { me acostumo mesmo, toda vez que no nosso serviço falece algum paciente } \\
\text { eu fico angustiado por ter que dar a notícia. Então, quando o paciente } \\
\text { falece, liga para a família e o pessoal me fala: 'oh, a família do paciente está } \\
\text { lá esperando a notícia.' Essa parte é a mais triste, é a pior hora do plantão } \\
\text { médico, da atuaçáo médica, da nossa profissão. Dar essa notícia me deixa } \\
\text { sempre muito chateado. [...] E chega aqui você tem que falar que o doente } \\
\text { morreu, isso é muito difícil, é muito triste. [...] É difícil dar uma notícia } \\
\text { para a família de um óbito de criança, ainda mais uma criança saudável, } \\
\text { sem doença nenhuma, é picada por um escorpião e morre." (E35, Clínica } \\
\text { Médica, M, } 69 \text { anos) }\end{array}$ \\
\hline Desculpar-se & $\begin{array}{l}\text { "À medida em que eu comuniquei a parte final do falecimento, eu viro para } \\
\text { eles, peço desculpas [...] eu sempre acho que eu podia ter feito mais." (E16, } \\
\text { Neurocirurgia, M, } 32 \text { anos) }\end{array}$ \\
\hline Desgastar-se & $\begin{array}{l}\text { "É uma coisa que consome bastante, tira as energias da gente." (E21, Clínica } \\
\text { Médica, M, } 34 \text { anos) }\end{array}$ \\
\hline Fugir & $\begin{array}{l}\text { "O residente pode dar a notícia, mas na maioria das vezes ele foge, você vê } \\
\text { muito residente fugindo, é a hora mais temida: a do óbito." (E34, Clínica } \\
\text { Médica, F, } 29 \text { anos) }\end{array}$ \\
\hline Esconder-se & $\begin{array}{l}\text { "O médico de pronto-socorro coloca um escudo na frente dele, que é o } \\
\text { escudo da urgência e da emergência [...] Mas é o escudo, é para não se expor, } \\
\text { para não perder tempo, para não se desgastar, não sofrer, para deixar as suas } \\
\text { questóes de morte guardadas." (E33, Terapia Intensiva, F, } 34 \text { anos) }\end{array}$ \\
\hline Incomodar-se & $\begin{array}{l}\text { "Agradável não é [...]. Ninguém gosta disso, mas faz parte [...] eu preferiria } \\
\text { que ninguém morresse no meu plantão, mas eu não sou mágico para } \\
\text { conseguir isso." (E10, Cirurgia Geral, M, } 39 \text { anos) }\end{array}$ \\
\hline Rezar & $\begin{array}{l}\text { "Eu rezo para não ter que me apresentar na hora do óbito." (E36, Pediatria, } \\
\text { M, } 46 \text { anos) }\end{array}$ \\
\hline
\end{tabular}

Fonte: Elaborado pelas autoras.

Assim, no ato da comunicação o médico reconhece e é tocado pela reação do outro. Trata-se de uma experiência afetiva, como nesta fala:

$\mathrm{Na}$ parte profissional, eu me sinto um pouco preparada, mas toda vez que eu vou dar notícia de óbito para uma família, meu olho acaba enchendo de lágrima, eu fico meio engasgada com toda aquela dor ali na minha frente. (E42, Clínica Médica, F, 28 anos) 
Diante da família de um morto, nota-se o paradoxo entre o profissional — que, segundo os preceitos biomédicos, deveria cuidar do paciente como um caso ou um órgão - e o ser humano, dotado de emoções e compaixão (LE BRETON, 2009). Os médicos adiam ao máximo comunicar a morte por receio de se envolverem na cadeia de emoçôes e comprometerem seu autocontrole (ARIÈS, 2014).

Uma das maneiras de agir é assumindo o papel de "agenciador da esperança" (Diário de campo, 2013) e também por isso não se sentem confortáveis em comunicar a morte. A sociedade ocidental recusa-se a reconhecer o luto, interdita as manifestaçóes das emoçóes no hospital, lugar em que soam como inadequadas, seja por parte do doente, de seus familiares ou dos profissionais (SILVA; MENEZES, 2015; ARIĖS, 2014; LE BRETON, 2009). Porém, a prática comunicativa sobre a morte ultrapassa a delimitação informacional de transmissão de mensagens e abrange uma interação complexa com diferentes significados entre os sujeitos culturais (AREDES; MODESTO, 2016; PITTA, 2016).

A morte aparece como terreno obrigatório de expressão de emoçóes contraditórias. Culturalmente, é previsto o agir do profissional perante o moribundo e seus familiares (TIMMERMANS, 2005), mas o médico também é um ser humano confrontado com o sofrimento próprio e alheio (LE BRETON, 2009). Nesse sentido, o saberfazer médico precisa aliar a técnica do modelo biomédico à capacidade de ser "humano", de modo a integrá-los na prática do cuidado (AFONSO; MINAYO, 2013; LE BRETON, 2009).

Perguntada acerca da dificuldade em comunicar a morte, esta médica esclarece:

Não tenho dificuldade de dar a notícia. Quando é um caso muito grave, às vezes, a gente fica mais tenso [...] eu náo tenho dificuldade em abordar a pessoa, mas, às vezes tenho dificuldade em dar a notícia ruim. [...] Não tem jeito, e é complicado, pois não é fácil você dar a notícia de um óbito, principalmente aqueles bem inesperados. [...] Depois que disse que seu filho morreu e ele ficou olhando para mim, eu fui chamar a assistente social e fui ao banheiro chorar sozinha, eu não tinha o que fazer mais. (E23, Clínica Médica, F, 57 anos).

Revela-se, portanto, a contradição entre a fala e a ação. Inverso ao que é superficialmente observado, apreendido e esperado da atuação do médico na emergência, como sujeitos resistentes, essa significação se contrapóe ao modo como agem - ainda que escondido no hospital, durante as entrevistas ou mesmo em casa. Essas incongruências entre o pensar e o agir se revelam no uso de "máscaras" para administrar seu afeto e de mecanismos defensivos para minimizar as condiçóes 
desfavoráveis e a sobrecarga emocional em seu trabalho (AREDES; MODESTO, 2016; PITTA, 2016; MONTEIRO et al., 2015; LAMBA et al., 2015; DELL'ACQUA; TOME; POPIM, 2013; DESLANDES, 2002).

Porém, enquanto comunicam a morte aos familiares, os profissionais externam uma ampla gama de reaçóes e emoçôes, tais como o sentimento de fracasso por não ter cumprido seu dever de salvar vidas, tristeza, impotência, perda, desgaste, adoecimento, medo, ansiedade, automatismo, angústia, compaixão, conflito, desamparo, luto, sofrimento pela própria mortalidade, dificuldade em lidar com a reação de dor do familiar e com os questionamentos quando a causa da morte é desconhecida (LAMBA et al., 2015; SILVA; RAMOS, 2014; SHOENBERGER et al., 2013).

Uma das limitaçôes deste estudo é não investigar a recepção da comunicação. Além disso, seria impossível alcançar plenamente a amplitude das especificidades da morte no cenário eleito, uma vez que ela sofre a influência de quem é a pessoa que morre, em qual situação, contexto e local em que o óbito ocorre.

\section{Consideraçôes Finais}

Neste estudo visualiza-se que a morte permanece um assunto tabu. No hospital de emergência investigado, o processo de comunicação da morte revela-se envolto por dificuldades que não se referem às informaçôes técnicas e ao repasse da notificação do óbito biológico, mas de uma ação que agrega aspectos humanos, intersubjetivos, psicossociais e culturais. Em campo, isso se dá mediado por embaraços e ambivalências entre os modos de pensar e agir dos profissionais.

Fica evidente a necessidade de humanizar a assistência de modo mais efetivo, promovendo a reflexão acerca dos efeitos deletérios da obstinação terapêutica, bem como as consequências na saúde física e mental dos médicos que têm a morte como integrante da rotina profissional.

A difícil tarefa de comunicar o óbito no contexto da urgência revela o médico enquanto sujeito cultural dotado de emoçôes, o que, em cascata, influencia nas habilidades interpessoais, comunicacionais e no próprio cuidado. Isso incita intervençôes no âmbito da formação médica, da saúde do trabalhador e da organização do serviço que contemplem os limites da medicina e flexibilizem o paradigma biomédico em prol de uma atenção integral em um hospital de emergência. ${ }^{1}$ 


\section{Referências}

AFONSO, S. B.C.; MINAYO, M. C. S. Notícias difíceis e o posicionamento dos oncopediatras: revisão bibliográfica. Ciência \& Saúde Coletiva. Rio de Janeiro, v. 18, n. 9, p. 2747-2756, 2013. ALELWANI, S. M.; AHMED, Y. A. Medical training for communication of bad news: a literature review. International Journal of Health Promotion and Education, v. 3, n. 51, p. 1-5, June 2014.

ARAÚJO, I. S.; CARDOSO, J. M. Comunicação e Saúde. Rio de Janeiro: Editora Fiocruz, 2007, 152p. (Coleção Temas em Saúde).

AREDES, J. S.; GIACOMIN, K. C.; FIRMO, J. O. A. A práxis médica no pronto atendimento diante do paciente com sequelas crônicas: culpa, temor e compaixão. Revista Trabalho, Educação e Saúde, v. 16, n. 3, p. 1177-1199, set./dez., 2018.

AREDES, J. S.; MODESTO, A. L. "Entre vidas e mortes, entre máscaras e fugas”: um estudo sobre a prática médica hospitalar. Physis: Revista de Saúde Coletiva. Rio de Janeiro, v. 26, n. 2 , p. 435-453, 2016.

ARIÈS, P. O homem diante da morte. 1ed. Tradução: Ribeiro, L. São Paulo: Unesp; 2014. 837p.

ASCENCIO-ROMERO, M. C. et al. Brindar malas noticias en la sala de emergencias. An Fac Med., v. 76, n. 1, p. 85-6, 2015.

CAMARGO JR, K. R. O paradigma clínico-epidemiológico ou biomédico. Revista Brasileira de História da Ciência, v. 6, p. 183-195, 2013.

CORIN, E. et al. Articulation et variations des systèmes de signes, de sens et d'actions. Psychopathologie Africaine, v. 24, n. 2, p. 183-204, 1992.

DELL'ACQUA, M. C. Q; TOME, L. Y.; POPIM, R. C. O processo de trabalho em urgência e emergência em interface com a morte. Revista da Rede de Enfermagem do Nordeste, Fortaleza, v. 14, n. 6, p. 1149-1159, 2013.

DESLANDES, S. F. Frágeis deuses: profissionais da emergência entre os danos da violência e a recriação da vida. Rio de Janeiro: Fiocruz, 2002. 194p.

FALCONI-CHALCO, E. M. Guía para comunicar a familiares la muerte repentina en emergencia. Anales de la Facultad de Medicina, v. 74, n. 3, p. 217-220, jul. 2013.

FORERO, R. et al. A literature review on care at the end-of-life in the Emergency Departament. Emergency Medicine International, Article ID 486516, 11p. 2012. doi: 10.1155/2012/486516

GEERTZ, C. A Interpretação das Culturas. Rio de Janeiro: LTC, 1989. 213p. (Antropologia Social).

ILLICH, I. Medical nemesis. Journal of Epidemiology \& Community Health, v. 57, n. 12, p. 919-922, 2003. 
LAMBA, S. et al. Structured communication: teaching delivery of difficult news with simulated resuscitations in nan Emergency Medicine Clerkship. Western Journal of Emergency Medicine, v. 16, n. 2, p. 344-352, 2015.

LE BRETON, D. As paixóes ordinárias: antropologia das emoções. Tradução: Peretti, L. A. S. Rio de Janeiro: Vozes, 2009. 276p.

LIMEHOUSE, W. E. et al. A model for emergency department end of life communications after acute devastating events - Part II: moving from resuscitative to end of life or palliative treatment. Academic Emergency Medicine, v. 19, n. 11, p. 1300-8, 2012.

MINAYO, M. C. S. Amostragem e saturação em pesquisa qualitativa: consensos e controvérsias. Revista Pesquisa Qualitativa, São Paulo, v. 5, n. 7, p. 1-12, 2017.

MONTEIRO, D. T. et al. Morte: o difícil desfecho a ser comunicado pelos médicos. Estudos e Pesquisas em Psicologia, v. 15, n. 2, p. 547-567, 2015.

NORDBY, H.; NOHR, O. Communication and empathy in an emergency setting involving persons in crisis. Scandinavian Journal of Trauma, Resuscitation and Emergency Medicine, v. 16, n. 5, 2008.

PATTON, M. Q. Qualitative research and evaluation methods. 3ed. London: Sage, 2002. 598p. PEREIRA, C. R. et al. The P-A-C-I-E-N-T-E Protocol: An instrument for breaking bad news adapted to the Brazilian medical reality. Revista da Associação Médica Brasileira, v. 63, n. 1, p. 43-49, 2017.

PITTA, A. Hospital: dor e morte como oficio. $7^{a}$ ed. São Paulo: Hucitec, 2016. 198p.

REYNIERS, T. et al. The acute hospital setting as a place of death and final care: a qualitative study on perspectives of Family physicians, nurses and Family careers. Elsevier Health \& Place, v. 27, p. 77-83, 2014.

SANTOS, M. J. M; MORAES, E. L.; MASSAROLLO, M.C.K. Comunicação de más notícias: dilemas éticos frente à situação de morte encefálica. Mundo saúde, v. 36, n. 1, p. 34-40, 2012.

SHOENBERGER, J. M et al. Death notification in the emergency department: survivors and physicians. Western Journal of Emergency Medicine, v. 14, n. 2, p. 181-185, 2013.

SILVA, N. R.; MENEZES, R. A. "Se parar, parou”: categorização do morrer em uma unidade de terapia intensiva da cidade do Rio de Janeiro. Physis: Revista de Saúde Coletiva, v. 25, n. 1, p. 265-285, 2015.

SILVA, S. M.; RAMOS, M. Z. Profissionais de saúde de um serviço de emergência hospitalar: discursividades em torno do cuidado. Physis: Revista de Saúde Coletiva, v. 24, n. 3, p. 693-714, 2014. STELET, B. P.; CASTIEL, L. D., MORAES, D. R. Anomalisa e o ensino da comunicação clínica na prática médica. Cad Saúde Pública, v. 33, n. 2, e00154016, 2017. 
TAPAJÓS, R. A comunicação de notícias ruins e a pragmática da comunicação humana: o uso do cinema em atividades de ensino/aprendizagem na educação médica. Interface - Comunicação, Saúde, Educação, v. 11, n. 21, p. 165-172, 2007.

TIMMERMANS, S. Death brokering: constructing culturally appropriate deaths. Sociology of Health \& Illness, p. 993-1013, 2005.

UCHÔA, E.; VIDAL, J. M. Antropologia médica: elementos conceituais e metodológicos para uma abordagem da saúde e da doença. Cadernos de Saúde Pública, v. 10, n. 4, p. 497-504, 1994.

\section{Nota}

${ }^{1}$ G. A. Souza trabalhou na concepção e planejamento do projeto, análise e interpretação dos dados; contribuiu na elaboração do manuscrito e aprovação de sua versão final. K. C. Giacomin e J. O. A. Firmo participaram da concepção e planejamento do projeto, análise e interpretação dos dados; revisão crítica relevante do conteúdo intelectual; e aprovaram a versão final do manuscrito. J. de S. Aredes trabalhou na concepção e planejamento do projeto, coleta análise e interpretação dos dados; na revisão crítica relevante do conteúdo intelectual; e participou da aprovação da versão final do manuscrito. 


\section{Abstract}

\section{Communication of death: ways of thinking and acting of physicians in an emergency hospital}

This study aimed to understand how physicians deal with the process of communicating death to relatives in an emergency hospital. It is a qualitative research, based on interpretive and medical anthropology. The data were collected in one of the largest public hospitals in Latin America, during nine months of participant observation. A total of 43 physicians were interviewed. The analysis was emic and guided by the model of signs, meanings and actions. Although death is a frequent event due to the seriousness of the cases being attended to, doctors perceive the experiences of the communication of death as one of the most arduous tasks of their professional practice. They use scripts, euphemisms, defensive mechanisms, emphasize clinical severity and progressively report on the worsening of the condition, so that death is expected by the family and embedded in the emergency routine. Signs and meanings are especially correlated to the biomedical paradigm, regarding it as taboo and failure, while actions evidence death and intersubjective interaction as a compulsory terrain of emotions, which occur hidden by the professional. The mentioned elements can subsidize interventions, planning and management in health care, in the field of education, workers' health and institutional organization.

Keywords: death; communication; medical anthropology; emergency service; hospital; physicians. 